\title{
A Noninvasive Method For Monitoring Intestinal Ischemia: Changes in the Pulmonary Clearance of Helium Instilled into the Colon as an Index of Colonic Blood Flow
}

\author{
DALE R. GERSTMANN, FEIZAL WAFFARN, ROBERT F. HUXTABLE, AND \\ ANTHONY V. BERAN
}

Neonatology, University of California Irvine, Orange, California 92668

\begin{abstract}
To evaluate the concept that changes in colonic blood flow will predictably alter the absorption of colonic gas, we measured the pulmonary clearance rate of helium $\left(\mathrm{C}_{\mathrm{He}}\right)$ which was instilled rectally into the colon of rabbits at a dose of $2 \mathrm{ml} / \mathrm{kg}$. $C_{\mathrm{HE}}$ reached a plateau after $20 \mathrm{~min}$ at $109 \mathrm{nmol} / \mathrm{min} / \mathrm{kg}$. Using hypoxemia as a cause for bowel ischemia, at $\mathrm{PAO}_{2}=38$ torr, we noted a marked decrease in $\mathrm{C}_{\mathrm{He}}$ from $110 \mathrm{nmol} / \mathrm{min} / \mathrm{kg}$ to $75 \mathrm{nmol} / \mathrm{min} / \mathrm{kg}$ $(p<0.025)$. Because helium absorption from the colon is diffusion limited, a model can be developed relating "subvillus" colonic blood flow to pulmonary helium clearance. From this model we would predict the hypoxemia induced change in $\mathrm{C}_{\mathrm{He}}$ to be secondary to colonic hypoperfusion. This type of indirect monitoring could be useful in detecting patients with bowel ischemia. (Pediatr Res 19: 1025-1028, 1985)
\end{abstract}

\section{Abbreviations}

\author{
He, helium \\ $\mathrm{C}_{\mathrm{He}}$, helium clearance \\ $\dot{\mathrm{V}}_{\mathrm{T}}$, total minute ventilation \\ [He] $]_{e e}$, end-expiratory $\mathrm{C}_{\mathrm{He}}$ \\ $F_{\text {sv }}$, subvillus flow \\ $\mathrm{H}_{2}$, hydrogen gas \\ ppm, parts per million
}

The capability to measure clinically intestinal blood flow has many potential benefits in patients who have had known hypoxemic or hypotensive insults. One such group of patients would be small premature infants whose adequate nutritional status depends largely on the early institution of enteral feedings. Because prenatal and natal physiologic events may create states of intestinal ischemia which can predispose to bowel injury, development of a method for monitoring intestinal hypoperfusion may help reduce morbidity by giving useful clinical information to direct neonatal bowel resuscitation and to establish the timeliness of gastrointestinal use. It is possible that the early use of the hypoperfused gut for enteral nutrition may result in the specific complication of necrotizing enterocolitis, the etiology of which is believed to be a combination of bowel ischemia, luminal carbohydrate substrate, and bacterial growth with fermentation and tissue invasion. Our study was therefore undertaken to develop a method of assessing changes in intestinal circulation

Received February 25, 1985; accepted May 24, 1985.

Reprint requests Dale R. Gerstmann, Major, USAF, MC, Neonatology, Wilford Hall USAF Medical Center, Lackland Air Force Base, TX 78236-5300. which could be used on the neonatal patient. This necessitated developing a clinically applicable not noninvasive technique. The underlying principle for the technique is that pulmonary clearance of an inert gas instilled into the colon is predictably altered by changes in colonic blood flow and that the state of colonic blood flow in the segment measured is at least an indicator of regional gut perfusion.

The concept of using bowel gas absorption to reflect bowel perfusion has previously been applied in both animals and in man. Animal studies examining the relationship between intestinal gas absorption and bowel blood flow have typically used techniques requiring surgical exteriorization of a bowel segment (1-5). Similar bowel exteriorization studies have been performed on adult humans undergoing laparotomy and have involved measuring pulmonary gas excretion following gas instillation into the jejunum or colon (6). In the present study, $\mathrm{He}$, a passively absorbed inert gas, was instilled rectally into the colon of rabbits, and its pulmonary clearance was measured by end-expiratory breath sampling.

We then examined changes in $\mathrm{C}_{\mathrm{He}}$ during hypoxemia, and insult which is known to cause decreased mesenteric perfusion and bowel ischemia (7). This relationship between pulmonary clearance of colonically absorbed gas and effective subvillus colonic blood flow is discussed in terms of a currently available model for inert gas absorption, and it can be shown that endexpiratory levels should reflect changes in subvillus blood flow in minute-ventilation is known.

\section{METHODS}

Technique. Nine New Zealand White rabbits less than 4 months of age and weighing between $2.4-2.9 \mathrm{~kg}$ were used in the experiments. Five control and four study animals were prepared with pentobarbital anesthesia and ketamine sedation. Following this, a 4-mm uncuffed tracheostomy tube was placed and secured tightly with ligature to prevent airleak. The animals were paralyzed with curare and connected to a Bourn's model LS104 infant volume respirator. Oxygenation was controlled by a variable oxygen:nitrogen gas source. A femoral arterial catheter was established for monitoring $\mathrm{pH}, \mathrm{PAO}_{2}$ and $\mathrm{PACO}_{2}$. An in-line pneumotachometer ws placed in the tracheostomy tube to measure tidal volume and respiratory rate.

Intermittent end-expiratory breath samples were obtained from a sampling catheter made of $8 \mathrm{~cm}$ of $2 \mathrm{~mm}$ polyethylene tubing inserted through the tracheostomy tube, with the tip positioned at the level of the vocal cords. The catheter deadspace was first cleared by aspiration of $0.5 \mathrm{ml}$ per breath at endexpiration over three to five ventilations via a stopcock and plastic syringe. After clearing of the catheter, $6 \mathrm{ml}$ of end- 
expiration breath was collected in $0.5 \mathrm{ml}$ increments over 12 ventilations.

Analysis of the breath sample was done using a model 111 Carle analytical gas chromatograph equipped with a thermoconductivity detector and using nitrogen gas as the carrier. An attached chart recorder provided graphic readout. Calibration was done using analytical grade helium $(150.0 \pm 0.1 \mathrm{ppm})$, while nitrogen was used to check for zero background. Linear correlation of diluted samples of calibration gas was excellent, as was the reproducibility of multiple determinations of the same sample. Atmospheric He concentration $(5.0 \mathrm{ppm})$ was subtracted from the measured peak height.

A rectal tube was inserted to a distance of $12-15 \mathrm{~cm}$ for instillation of He gas. The tube was a modified $4.5 \mathrm{~mm}$ cuffed endotracheal tube which was occluded at the distal end except for the orifice of a $2 \mathrm{~mm}$ polyethylene tube. He was instilled through this tube via a stopcock. Use of the small tubing minimized the dead-space of the larger rectal tube. Rectal leakage of the instilled gas was prevented by inflation of the cuff.

Protocol. The experimental protocol is shown graphically in Figure 1. During a 1 -h stabilization period the inspiratory gas mixture and ventilator settings were adjusted to maintain oxygenation and ventilation in the normal range: $\mathrm{pH} 7.33-7.73$, $\mathrm{PAO}_{2} 79-108$ torr, $\mathrm{PACO}_{2}$ 11.2-28.2 torr (8). Once stable, no further ventilator changes were made. Ventilator rate and tidal volume were monitored for calculation of $\dot{V}_{\mathrm{T}}$. A bolus of 90 $\mu \mathrm{mol} / \mathrm{kg}(2 \mathrm{ml} / \mathrm{kg})$ of $\mathrm{He}$ gas was injected into the distal colon via the rectal tube, and baseline $[\mathrm{He}]_{\mathrm{ee}}$ were measured at $10-\mathrm{min}$ intervals. Arterial pH and blood gases were obtained every 15-20 min. Following $60 \mathrm{~min}$ of baseline data collection the study animals were made hypoxic by adjusting the oxygen:nitrogen gas ratio to between 0.13 to $0.17 \mathrm{FrO}_{2}$, which resulted in a range of arterial $\mathrm{pO}_{2}$ values between $30-40$ torr. Data were collected on all animals for another $90 \mathrm{~min}$ at $10-\mathrm{min}$ intervals. Mean and SDS were calculated and plotted versus time, and differences between means were analyzed by $t$ test for statistical significance at the $p<0.05$ level.

Total pulmonary $\mathrm{C}_{\mathrm{He}}$ was calculated from end-expiratory helium concentrations by the following formula (9):

$$
\begin{aligned}
\mathrm{C}_{\mathrm{He}} & =[\mathrm{He}]_{\text {ave }} \times \dot{\mathrm{V}}_{\mathrm{T}} \\
& =\mathrm{k} \times[\mathrm{He}]_{\mathrm{ee}} \times \dot{\mathrm{V}}_{\mathrm{T}}
\end{aligned}
$$

when $\mathrm{k}$ is a constant related to the ratio of deadspace and alveolar volume, and was found in preliminary experiments to be $0.50-$ 0.53 for our rabbit preparation.

He absorption model. The relationship between colon blood flow and inert gas clearance can be developed and examined through modeling of colon gas absorption dynamics. One such model for passive absorption of gas from the bowel has been proposed and refined by Levitt and coworkers (2-5). This model encompasses three major determinants: blood flow dependent absorption of the villus tip, counter-current exchange within the villus, and diffusion dependent absorption directly into the subvillus space (5). Considering the second determinant, the influence on absorption of counter-current exchange depends both on the "exposure" of the villus to the bowel lumen and on the diffusivity of the gas. In situations analogous to our experiment where only the villus tip is exposed (colon), and where highly

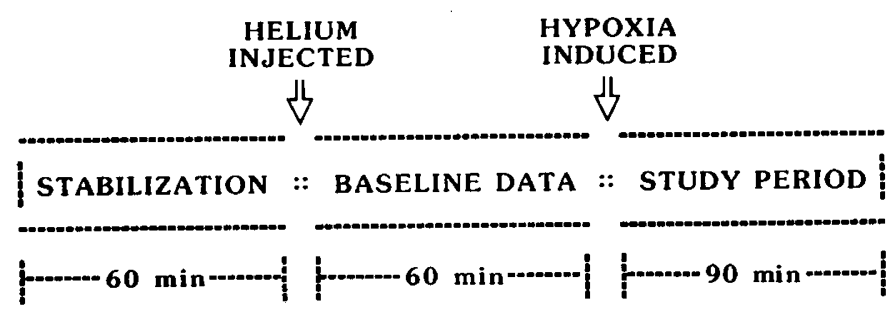

Fig. 1. Experimental time segments and protocol sequence. diffusable gases are used $\left(\mathrm{H}_{2}, \mathrm{He}\right)$, passive gas absorption is almost entirely diffusion limited $(2,5)$. In this situation the efficiency of the counter-current mechanism is near perfect, negating any contribution to absorption by the first determinant, namely blood flow at the villus tip. This then allows approximation of gas absorption through consideration of only the third determinant, which is the diffusive component. Thus, in an adaptation from Levitt and Levitt (5) we can write the diffusive component as:

$$
\mathrm{Q}_{\mathrm{D}}=\mathrm{J} / \mathrm{V} \times\left(\mathrm{P}_{\mathrm{t}}-\mathrm{P}_{\mathrm{sv}}\right) / \mathrm{P}_{1}
$$

where $Q_{D}=$ diffusive component of gas absorption; $J=a$ constant dependent on bowel architecture and gas diffusivity; $\mathrm{V}=$ volume of instilled gas; $P_{t}=$ partial pressure of gas at the villus tip; $P_{1}$, partial pressure of gas in the bowel lumen; $P_{s v}=$ partial pressure of gas in the subvillus space.

Since for helium, $P_{t}=P_{1}(5)$ the expression can be written as:

$$
\begin{aligned}
& \mathrm{Q}_{\mathrm{D}}=\mathrm{J} / \mathrm{V} \times\left(1-\mathrm{P}_{\mathrm{sv}} / \mathrm{P}_{1}\right), \text { or } \\
& \mathrm{P}_{\mathrm{sv}}=\mathrm{P}_{1} \times\left(1-\mathrm{Q}_{\mathrm{D}} \mathrm{V} / \mathrm{J}\right)
\end{aligned}
$$

Following absorption, the amount of gas cleared by perfusion equivalent to some "effective" $F_{\mathrm{sv}}$ can be expressed as:

$$
\mathrm{C}_{\mathrm{sv}}=\left(\mathrm{k}^{\prime} \times \mathrm{P}_{\mathrm{sv}}\right) \times \mathrm{F}_{\mathrm{sv}}
$$

With $\mathrm{C}_{\mathrm{sv}}$ equal to the subvillus clearance of $\mathrm{He}$, and $\mathrm{k}^{\prime}$ being the Bunsen gas solubility constant. Combined with equation II, equation III thus becomes:

$$
\begin{aligned}
\mathrm{C}_{\mathrm{sv}} & =\mathrm{F}_{\mathrm{sv}} \times\left(1-\mathrm{Q}_{\mathrm{D}} \mathrm{V} / \mathrm{J}\right) \times\left(\mathrm{k}^{\prime} \times \mathrm{P}_{1}\right) \\
& =\mathrm{F}_{\mathrm{sv}} \times\left(1-\mathrm{Q}_{\mathrm{D}} \mathrm{V} / \mathrm{J}\right) \times[\mathrm{He}]_{1}
\end{aligned}
$$

This is to say that the effective subvillus clearance is some fraction, $\left(1-Q_{D} V / J\right)$, of the interluminal concentration, $[\mathrm{He}]_{1}$ $=\left(\mathrm{k}^{\prime} \times \mathrm{P}_{1}\right)$, and proportional to the effective $\mathrm{F}_{\mathrm{sv}}$. Assuming no loss of $\mathrm{He}$ from the circulation, the fraction of absorbed gas carried by $F_{s v}$ will enter the portal, central venous, and then pulmonary circulation. Because of the gas:liquid solubility characteristics, the partition coefficient for He would predict $>99 \%$ of the gas to be cleared by the lungs, and recirculation to be minimal. Thus, total pulmonary clearance of the gas, $\mathrm{C}_{\mathrm{He}}$, must equal the subvillus clearance, $\mathrm{C}_{\mathrm{sv}}$ :

$$
\begin{aligned}
\mathrm{C}_{\mathrm{He}} & =\mathrm{C}_{\mathrm{sv}} \\
& =\mathrm{F}_{\mathrm{sv}} \times\left(1-\mathrm{Q}_{\mathrm{D}} \mathrm{V} / \mathrm{J}\right) \times[\mathrm{He}]_{1}
\end{aligned}
$$

From equation I,

$$
\mathrm{k} \times[\mathrm{He}]_{\mathrm{ee}} \times \dot{\mathrm{V}}_{\mathrm{T}}=\mathrm{F}_{\mathrm{SV}} \times\left(1-\mathrm{Q}_{\mathrm{D}} \mathrm{V} / \mathrm{J}\right) \times[\mathrm{He}]_{1}
$$

rearranging,

$$
[\mathrm{He}]_{\mathrm{ee}}=\mathrm{F}_{\mathrm{sv}} \times\left(1 / \mathrm{kV}_{\mathrm{T}}\right) \times\left(1-\mathrm{Q}_{\mathrm{D}} \mathrm{V} / \mathrm{J}\right) \times[\mathrm{He}]_{1}
$$

Equation IV determines the relationship between $\mathrm{C}_{\mathrm{He}}$ and colonic $F_{\text {sv }}$, while equation $V$ relates the measured quantity, end-expiratory helium concentration, to $F_{s v}$ and minute-ventilation. The terms $\left(1-Q_{D} V / J\right)$ and $[H e]_{1}$ are assumed to be relatively constant during the period of measurement.

\section{RESULTS}

During the baseline period, mean arterial $\mathrm{pH}$, and $\mathrm{PAO}_{2}$ were in physiologic range for both study and control animals and were not statistically different (Table 1). Slightly lower minute-ventilation in the control animals yielded higher carbon dioxide tensions, but this did not significantly effect $\mathrm{pH}$.

Within 20 min of decreasing the inspired oxygen concentration the mean arterial $\mathrm{PAO}_{2}$ in the study animals had fallen to 38 torr, significantly different from the baseline oxygenation in control animals of $99 \pm 24$ torr $(p<0.005)$, or in the study animals' own baseline values of $93 \pm 15$ torr $(p<0.005)$. Arterial 
Table 1. Minute-ventilation, oxygenation, and $C_{H e}($ mean $\pm S D)$

\begin{tabular}{lcc}
\hline \multicolumn{1}{c}{ Groups } & Control & Study \\
\hline$n$ & 5 & 4 \\
$\mathrm{Wt}(\mathrm{kg})$ & $2.67 \pm 0.16$ & $2.81 \pm 0.15$ \\
& & \\
Minute-ventilation & $355 \pm 71$ & $384 \pm 54$ \\
$(\mathrm{ml} / \mathrm{min} / \mathrm{kg})$ & & \\
$\mathrm{pH}$ & $7.39 \pm 0.02$ & $7.45 \pm 0.02$ \\
$\mathrm{PACO}_{2}$ (torr) & $37 \pm 9$ & $26 \pm 5$ \\
$\mathrm{PAO}_{2}$ (torr) & $99 \pm 24$ & $93 \pm 15$ \\
$\quad$ Normoxia & & $38 \pm 7$ \\
$\quad$ Hypoxia & & $(p=0.003)$ \\
& & \\
& & \\
$\mathrm{C}_{\mathrm{He}}$ & & $110 \pm 19$ \\
$(20$ min postchange) & & $75 \pm 13$ \\
(nmol/min/kg) & & $(p=0.024)$ \\
$\quad$ Normoxia & &
\end{tabular}

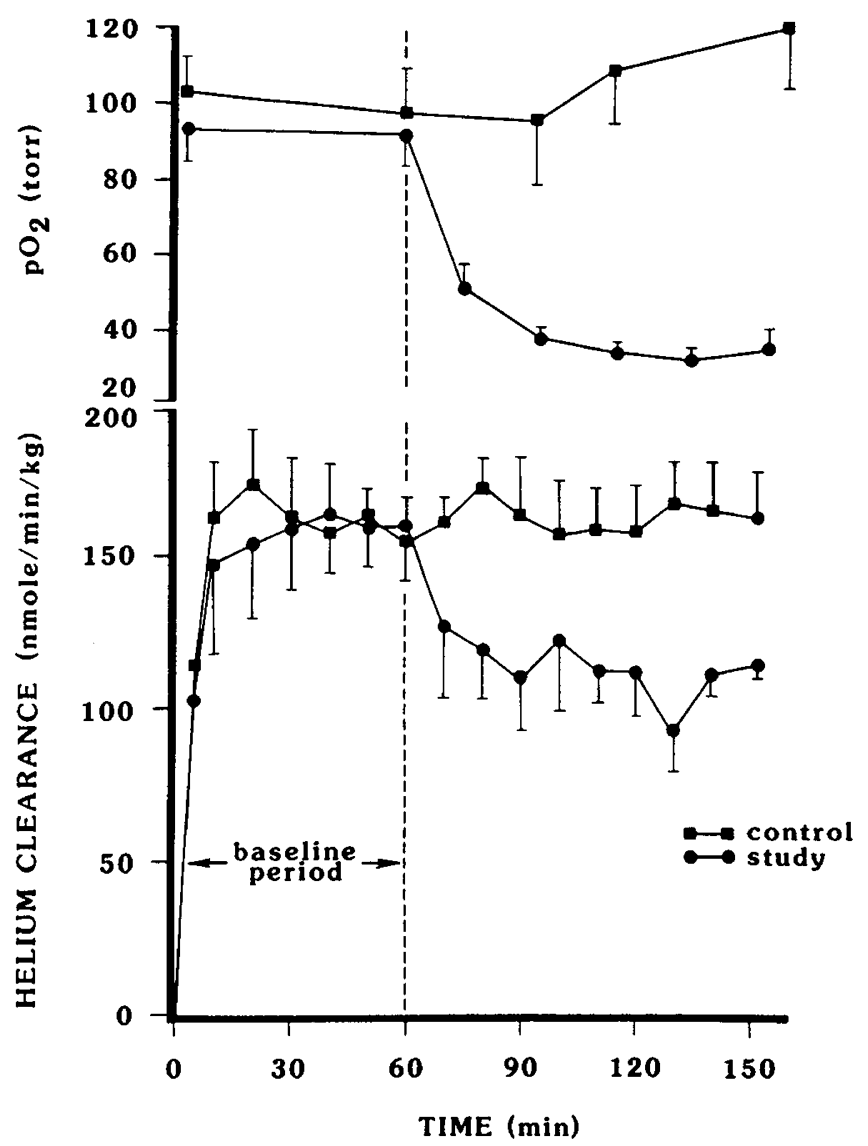

Fig. 2. Right, arterial oxygenation in study and control groups demonstrating induced hypoxemia in study animals and normoxia in control group. Left, pulmonary clearance following $\mathrm{Hel}$ instillation (baseline period). There is a significant decrease in clearance noted in the study group during hypoxemia. Theoretically this decrease correlates with reduction in colon blood flow secondary to the hypoxic insult.

hypoxemia was maintained in the study animals at a $\mathrm{PAO}_{2}$ of approximately 40 torr for the duration of the experiment (Fig. 2 right).

Following colonic instillation of $\mathrm{He}$, end-expiratory concentrations, and thus $\mathrm{He}$ pulmonary clearance, increased and then plateaued within 10-20 min (Fig. 2 left). The clearance plateau for both study and control animals was essentially identical during this period, with $\mathrm{C}_{\mathrm{He}}$ values of 109 and $110 \mathrm{nmol} / \mathrm{min} /$ $\mathrm{kg}$, respectively, $(p=\mathrm{NS})$ (Table 1$)$. However, with the onset of hypoxemia, $\mathrm{C}_{\mathrm{He}}$ dropped rapidly in the study animals (Fig. $2 B$ ). By 20 min after decreasing the inspiratory oxygen, and coinciding with the drop in arterial oxygenation, $\mathrm{C}_{\mathrm{He}}$ in study animals had fallen to an average level of $75 \mathrm{nmol} / \mathrm{min} / \mathrm{kg}$, or to $68 \%$ of the control value. This lower clearance persisted throughout the remainder of the experiment and was a statistically significant change $(p<0.025)$ compared to the pulmonary clearance during normoxemia.

\section{DISCUSSION}

Equation V from the Helium Absorption Model reflects the dependence of end-expiratory breath levels on subvillus blood flow, minute-ventilation, gas diffusion, and luminal gas concentration. This model predicts $\mathrm{He}$ breath levels to be proportional to colon subvillus flow if minute ventilation is known and when $Q_{D}$ and $[\mathrm{He}]_{1}$ are constant or changing slowly. In our experiment $\mathrm{V}_{\mathrm{r}}$ was fixed by choice of ventilator settings and did not contribute to changes in $\mathrm{C}_{\mathrm{He}}$. As a function of time, $[\mathrm{He}]_{1}$ and $\mathrm{QD}_{\mathrm{D}}$ would be expected to decrease, as more gas leaves the body. However, $[\mathrm{He}]_{1}$ and $Q_{D}$ vary only slowly with time because of a very small fractional absorption of the gas. These assumptions are born out in the present study by examining the character of the pulmonary clearance curve in the control animals. After an equilibrium period, $\mathrm{C}_{\mathrm{He}}$ reaches a plateau and remains constant for more than $150 \mathrm{~min}$. This implies that in situations where $F_{s v}$ is not expected to be changing, and $V_{T}$ is constant, $[\mathrm{He}]_{1}$ and $Q_{D}$ change slowly. An identical clearance relationship was seen by Bjorneklett and Jenssen (6) with large volume $\mathrm{H}_{2}$ gas instillations into the human adult colon. Bjorneklett and Jenssen (6) reported a $2 \%$ per $30-\mathrm{min}$ fractional clearance, or $0.0007 / \mathrm{min}$. In our study, the administered dose was $90 \mathrm{mmol} / \mathrm{kg}$, and the $\mathrm{C}_{\mathrm{He}}$ in both animal groups was about $110 \mathrm{nmol} / \mathrm{min} / \mathrm{kg} 20 \mathrm{~min}$ following $\mathrm{He}$ instillation. The calculated fractional clearance rate was therefore $(110 \mathrm{nmol} / \mathrm{min} / \mathrm{kg} / 90 \mathrm{mmol} / \mathrm{kg})=0.0012 / \mathrm{min}$. These values are similar and support the assumption that only a relatively small quantity of instilled gas is absorbed through the colon and then cleared by the lungs. Such small changes would again imply little effect on $[\mathrm{He}]_{1}$, and thus on $\mathrm{Q}_{\mathrm{D}}$, within the experimental time frame. Changes in $[\mathrm{He}]_{\mathrm{ee}}$ should therefore be related only to changes in $F_{\text {sv }}$.

Reductions in bowel blood flow can readily be expected in response to hypoxemia. Hypoxia/asphyxia-induced gut ischemia has been classically studied by Touloukian et al. (7) in piglets. In his animals, hypoxia was extreme (mean $\mathrm{PO}_{2}=26$ torr), causing reductions in segmental colonic blood flow of $55-65 \%$. Colonic "mucousal" blood flow was reduced to an even greater extent, roughly $80 \%$. Considering $\mathrm{C}_{\mathrm{He}}$ to be reflective of colonic blood flow, in our rabbit model with milder hypoxia $\left(\mathrm{PAO}_{2}=40\right.$ torr $)$ and no asphyxia, there was a $32 \%$ drop in $\mathrm{C}_{\mathrm{He}}$. This could be interpreted as an equivalent drop in "effective" $F_{\text {sv. }}$. Supportive evidence for the relationship between pulmonary clearance and $F_{\mathrm{sv}}$ is offered by Perman et al. (1) who have related breath excretion of $\mathrm{H}_{2}$ to bowel ischemia. During hypotensive and occlusive small bowel insults in dogs a linear decrease in $\left[\mathrm{H}_{2}\right]_{\mathrm{ee}}$ was noted with progressive hypotension, reaching $65 \%$ reduction from baseline $\left[\mathrm{H}_{2}\right]_{\mathrm{ee}}$ at $30 \%$ blood volume loss. Mesenteric vascular occlusion also produced a significant $61 \%$ reduction in baseline $\left[\mathrm{H}_{2}\right]_{\mathrm{ee}}$ levels. However, the use of hydrogen instead of He as a tracer gas might well complicate the relationship between $F_{\text {sv }}$ and pulmonary clearance. Hydrogen is produced and in some cases metabolized by bowel bacteria (7) and has been shown to have rapidly varying excretion rates in human infants on lactose containing formulas (10). Both of these problems would interfere in measuring gas clearance. In addition, hydrogen is highly explosive, and detonations of endogenous hydrogen during surgery have been reported (11). He seems a reasonable alternative, having gas diffusion characteristics similar to hydrogen, but being 
nonflammable and having no endogenous source. Atmospheric levels, however, are 10 times greater than for hydrogen $(5 \mathrm{ppm}$ He versus 0.45 ppm $\mathrm{H}_{2}$ ), and this must be taken into consideration when approximating $\mathrm{C}_{\mathrm{He}}$ from $[\mathrm{He}]_{\mathrm{ee}}(9)$.

Overall, however, the use of $\mathrm{He}$ to indirectly measure colon blood flow appears theoretically and experimentally feasible by use of the proposed noninvasive technique. Although refinements in $\mathrm{He}$ monitoring are available with use of industry available He mass-spectrometry, clinical applicability awaits specific flow correlation studies to finalize the relationship between $\mathrm{C}_{\mathrm{He}}$ and $\mathrm{F}_{\mathrm{sv}}$. The information available from routine bowel monitoring would have substantial utility in terms of surveillance for acute circulatory changes. The premature neonatal population which is at such high risk for bowel hypoperfusion states, may benefit greatly from this type of indirect, noninvasive monitoring.

\section{REFERENCES}

1. Perman JA, Waters LA, Harrison MR, Yee ES, Heldt GP 1981 Breath hydrogen reflects canine intestinal ischemia. Pediatr Res 15:1229-1233

2. Levitt DG, Bond JH, Levitt MD 1980 Use of a model of small bowel mucosa to predict passive absorption. Am J Physiol 239:G23-G29

3. Bond JH, Levitt DG, Levitt MD 1977 Quantitation of counter current exchange during passive absorption from the dog small intestine. J Clin Invest $59: 308-318$

4. Bond JH, Levitt DG, Levitt MD 1974 Use of inert gases and carbon monoxide to study the possible influence of counter current exchange on passive absorption from the small bowel. J Clin Invest 54:1259-1265

5. Levitt MD, Levitt DG 1973 Use of inert gases to study the interaction of blood flow and diffusion during passive absorption from the gastrointestinal tract of the rat. J Clin Invest 52:1852-1862

6. Bjorneklett A, Jenssen E 1980 Measurement of pulmonary hydrogen $\left(\mathrm{H}_{2}\right)$ and $\mathrm{H}_{2}$ diffusion from the small bowel and colon. Scand J Gastroenterol 15:817823

7. Touloukian RJ, Posch JN, Spencer R 1972 The pathogenesis of ischemic gastroenterocolitis of the neonate: Selective gut mucosal ischemia in the asphyxiated piglet. J Pediatr Surg 7:194-205

8. Strauss J, Beran AV, Baker R, Boydston L, Reyes-Sanchez JL 1971 Effect of hemorrhagic shock on renal oxygenation. Am J Physiol 221:1545-1550

9. Ostrander CR, Cohen RS, Hopper AO, Shahin SM, Kerner JA, Johnson JD, Stevenson DK 1983 Breath hydrogen analysis. A review of the methodologies and clinical applications. J Pediatr Gastroenterol Nutr 2:525-533

10. Murphy EL, Calloway DH 1972 The effect of antibiotic drugs on the volume and composition of intestinal gas from beans. Am J Dig 17:639-642

11. Stevenson DK, Cohen RS, Ostrander CR, Shahin SM, Kerner JA, Wetmore DL, Werner SB, Tomczyk M, Johnson JD 1982 A sensitive analytical apparatus for measuring hydrogen production rates. II. Application to studies in human infants. J Pediatr Gastroenteral Nutr 1:233-237 